\title{
Thermal analysis of a BIPV system by various modelling approaches
}

Ya Brigitte Assoa ${ }^{\mathrm{a}, *}$, Luigi Mongibello ${ }^{\mathrm{b}}$, Anna Carr ${ }^{\mathrm{c}}$, Bernhard Kubicek ${ }^{\mathrm{d}}$, Maider Machado ${ }^{\mathrm{e}}$, Jens Merten ${ }^{\mathrm{a}}$, Siwanand Misara ${ }^{f}$, Francesco Roca ${ }^{\mathrm{b}}$, Wendelin Sprenger ${ }^{\mathrm{g}}$, Martin Wagner ${ }^{\mathrm{d}}$, Shokufeh Zamini ${ }^{\mathrm{d}}$, Tomás Baenas ${ }^{\mathrm{h}}$, Philippe Malbranche ${ }^{\mathrm{a}}$

${ }^{a}$ CEA, LITEN, Department of Solar Technologies, F-73375 Le Bourget du Lac, France

${ }^{\mathrm{b}}$ ENEA, Piazzale E. Fermi, 80055 Portici, NA, Italy

${ }^{\mathrm{c}}$ ECN, P.O. Box 1, NL-1755 ZG Petten, Netherlands

${ }^{\mathrm{d}}$ Austrian Institute of Technology, AIT, Energy Department, Giefinggasse 2, Vienna 1210, Austria

e Energy and Environment Division, TECNALIA Research \& Innovation, Paseo Mikeletegi 2, 20009 San Sebastián, Spain

${ }^{\mathrm{f}} R E D$ D Division Systems Engineering and Grid Integration - Fraunhofer IWES, Koenigstor 59, D-34119 Kassel, Germany

${ }^{\mathrm{g}}$ Division Thermal Systems and Buildings - Fraunhofer Institute for Solar Energy Systems ISE, Heidenhofstr. 2, 79110 Freiburg, Germany

${ }^{\mathrm{h}}$ Applied Mathematics Department, University of Alicante, Carretera de S. Vicente del Raspeig s/n, 03690 S. Vicente del Raspeig, Alicante, Spain

\section{A R T I C L E I N F O}

\section{Article history:}

Received 19 September 2016

Received in revised form 17 June 2017

Accepted 24 July 2017

\section{Keywords:}

Building Integrated Photovoltaic (BIPV)

Thermal modelling

Accuracy

Electrical energy output

\begin{abstract}
A B S T R A C T
This work presents various models developed and implemented within the SOPHIA European project in order to thermally characterize PV modules in a rooftop BIPV configuration. Different approaches have been considered, including a linear model, lumped elements models and models that make use of commercial software solvers. The validation of the models performed by comparing the results of simulations with experimental data recorded on a test bench over an entire year is presented and discussed on a seasonal basis. The results have shown that all the models implemented allow achieving a good prediction of the PV modules back surface temperature, with the minimum value of the coefficient of determination $\mathrm{R}^{2}$ around $95 \%$ on a yearly basis. Moreover, the influence of season weather conditions and of the incident solar irradiance magnitude on the accuracy of the considered thermal models is highlighted. The major result of the present study is represented by the fact that it has been possible to perform a better thermal characterization of the BIPV module by tuning some of the heat transfer coefficients, such as those relative to the effects of the wind velocity, and to the evaluation of sky temperature.
\end{abstract}

(c) 2017 Elsevier Ltd. All rights reserved.

\section{Introduction}

Building-integrated photovoltaic (BIPV) systems ensure many functions normally covered by buildings construction materials, with the additional value represented by the production of electrical energy. In the last years, many countries have offered additional incentives for building-integrated photovoltaics, with respect to the support schemes (E.g. feed-in tariffs) relative to the non-integrated solutions, with the aim of spreading the use of such systems also at urban level. Moreover, many efforts have been made numerically and experimentally by engineers and researchers in order to sweeten the architectural impact of these systems (Stamenic et al., 2004; Aste et al., 2016). Nowadays, different solutions of BIPV systems characterized by different shapes and functions are present in the market. Nevertheless, these PV systems generally reach higher temperatures than stand-alone ones,

\footnotetext{
* Corresponding author.

E-mail address: ya-brigitte.assoa@cea.fr (Y.B. Assoa).
}

and as a consequence they can lead to a loss in electrical performance and a reduction of photovoltaic PV modules lifetime. For these reasons, a suitable and accurate thermal modelling of BIPV systems is of fundamental importance in order to evaluate their contribution to the reduction of building energy needs, aiming Net Zero Energy Building. Indeed, the accuracy of the thermal modelling of BIPV systems may have a considerable influence on the accuracy of their electrical energy output prediction.

BIPV systems temperature depends on several parameters, such as the thermal and optical properties of their constituting materials, the cells technology, the PV module configuration and installation methods and, of course, the environmental conditions. Thus, many models of different levels of complexity have been developed in the last years (Lamnatou et al., 2015; Debbarma et al., 2017).

Many models rely on the use of correlations which express the operating temperature of BIPV panels as a function of the irradiance, the ambient temperature, and the nominal operating cell temperature $\left(T_{N O C T}\right)$. This nominal temperature represents the 


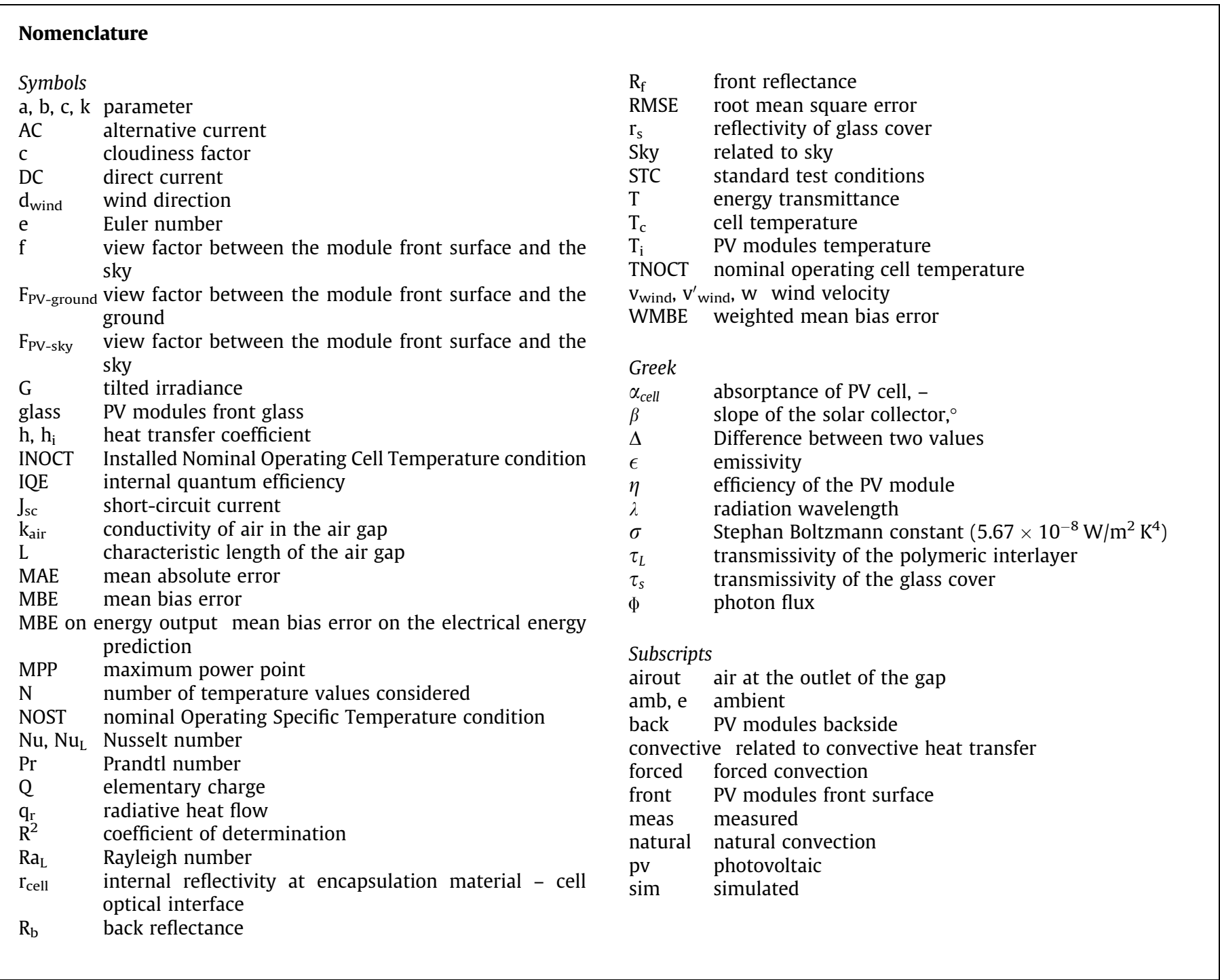

average temperature of PV modules for free-standing outdoor applications under Standard Operating Conditions (SOC), namely solar radiation of $800 \mathrm{~W} / \mathrm{m}^{2}$, ambient temperature of $20^{\circ} \mathrm{C}$, tilt angle of $45^{\circ}$, wind speed of $1 \mathrm{~m} / \mathrm{s}$, and open circuit operation (Lu and Yang, 2010; Drif et al., 2012; Masa-Bote and CaamañoMartín, 2014; Pantic et al., 2016). Other models rely on the use of empirical correlations which also include the effect of wind speed in order to calculate the operating temperature of the BIPV panel (Davis et al., 2003; Kaiser et al., 2014). A wide set of correlations employed for the calculation of operating temperatures of PV panels can be found in the work of Skoplaki and Palyvos (Skoplaki and Palyvos, 2009).

In other studies, the cell temperature is evaluated by implementing a lumped element model in order to solve the energy balance equation relative to the BIPV panel (Yoo, 2011; Chae et al., 2014; Wang et al., 2005; Chow, 2003; Assoa et al., 2013).

In some studies, the temperature field relative to BIPV panels is evaluated by means of commercial CFD solvers. This was made by Gan (2009), who used the commercial CFD solver Fluent 2005 for modelling of fluid flow and heat transfer around BIPV modules, and by Zhang et al. (2017), who derived a correlation for the convective heat transfer relative to a BIPV panel on the basis of the results of a CFD model realized using ANSYS Fluent 15.0.
Comparative studies of thermal models were also realized. Trinuruk et al. compared the accuracy of two commonly used thermal models developed for rack-mounted PV module in temperate climates when applied in different operating conditions, namely the SANDIA model and a NOCT model. Their application to three BIPV configurations in the tropical climate of Thailand showed that, in general, the SANDIA model gives better results than the NOCT model. (Trinuruk et al., 2009). Chatzipanagi et al. showed that the NOCT model and the Equivalent Cell Temperature model applied to various technologies and configurations of BIPV modules give good accuracy of temperature prediction (Chatzipanagi et al., 2016). Tuza and Mahieddine used four thermal models to determine the temperatures of free standing PV modules in the United Arab Emirates environmental conditions, and to evaluate the impact of the two best of them on power energy prediction. The Ross temperature model, two thermal models used by commercial software (Homers and PVSYST) as well as a three dimensional thermal model in COMSOL software were considered. Results indicate that all models underestimate the PV module temperature. The best results were obtained with the three dimensional model and the Homer model which gives the most accurate electrical power output of the PV modules when used in a two-diode electrical model (Tuza and Mahieddine, 2014). 
Sprenger et al. compared the results of two different models for the evaluation of the cell operating temperature of a BIPV system, one based on a linear correlation and the other one consisting in a lumped element model solving the energy balance equation relative to each layer composing the PV panel, with experimental ones. Further, as to the lumped element model, they also analyzed whether or not the variation of the external heat transfer coefficient with the measured wind speed and direction has sensible effects on results. They showed that the lumped element model produces better results than the linear model, and that, on average, the advantage of considering wind speed and direction is not large, except for particular days with high wind loads (Sprenger et al., 2016).

In this context, this study presents a comparison between the results of nine thermal models of a rooftop polycrystalline partially integrated BIPV system mounted on a test bench at INES site (Le Bourget du Lac). These models include a linear model, lumped elements models and models that make use of commercial software solvers. The experimental validation over an entire year of these models is presented and discussed on a seasonal basis. The main contribution of this work is represented by new insights on the thermal modelling of BIPV systems, coming from the comparison between the results relative to the different thermal modelling approaches used. Moreover, new correlations are proposed for the convective heat transfer coefficients based on the measured wind velocity, and the sky temperature evaluation as concerns the radiative heat transfer derived by comparing the numerical and experimental values in order to improve the accuracy of the thermal results.

\section{Experimentation}

\subsection{Description of the BIPV test bench}

The models implementation and the validation of numerical results have been accomplished by using the experimental database obtained by CEA INES at Le Bourget du Lac in France on a BIPV system composed of nine PV modules with polycrystalline silicon technology of about $2 \mathrm{kWp}$ (See Fig. 1).

The selected test bench is tilted at $15^{\circ}$, facing towards south.

The experimental facilities reflect a partial integration configuration of BIPV system in France. Compared to a fully integrated BIPV system, according to the French regulations in 2010, a BIPV system is said partially integrated if PV modules replace the

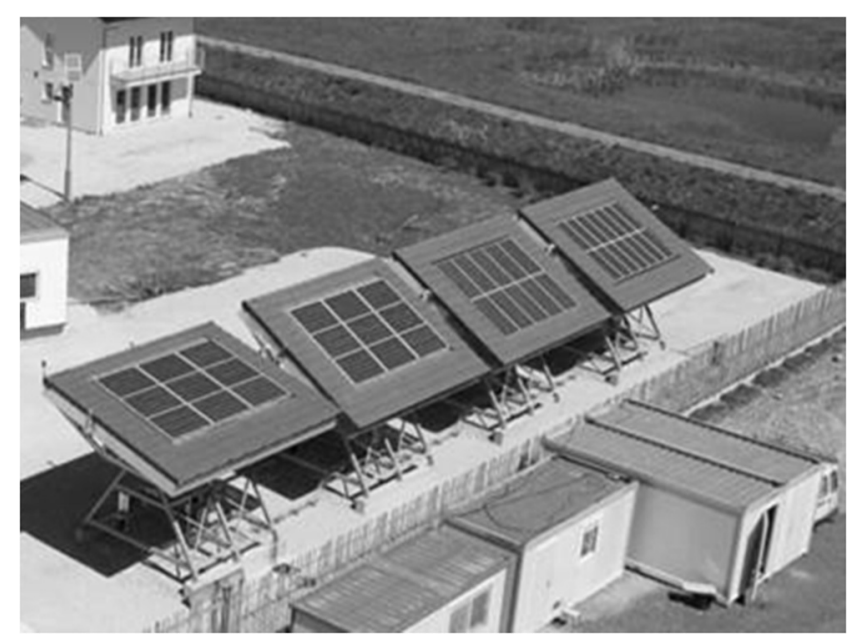

Fig. 1. Some BIPV test benches at CEA INES site (Le Bourget du Lac, France). existing roof tiles but have low contribution to the sealing function of the roof. Fig. 2 shows a cross-section of the test bench.

Two air layers separated by the integration structure exist between the PV modules and the roof insulation layer composed of nearly $30 \mathrm{~cm}$ of polystyrene. The upper air layer, namely the one between the modules and the integration structure, is $8 \mathrm{~cm}$ thick and it is open at the upper and the lower sides of the roof. It also presents very narrow apertures between the lateral sides of the modules. As to the lower air layer between the integration structure and the roof insulation layer, it is $12.2 \mathrm{~cm}$ thick and it is open in all the four sides.

The module dimensions are $166 \mathrm{~cm} \times 95 \mathrm{~cm} \times 0.475 \mathrm{~cm}$. Table 1 reports the material and the thickness of the layers constituting each PV module.

The experimental temperature data used were measured in 2011 on one PV module. Each PV module is equipped with a thermocouple (T-type thermocouples of JUMO with an uncertainty less or equal to $2 \%$ ) stuck at the center of the backside layer. Apart from these temperatures measurement, the instrumentation permitted to monitor the ambient temperature (PT100 sensors of TC direct with an uncertainty of more or less $0.1^{\circ} \mathrm{C}$, placed close to the test bench, on a higher plane), the global solar radiation on the test bench plane and on the horizontal plane (CMP11 of Kipp\&Zonen with an uncertainty of more or less $1.4 \%$ ), the wind velocity and direction close to the test bench at about $4.7 \mathrm{~m}$ above the ground (Windsonic with uncertainties of more or less $2 \%$ for wind velocity at $12 \mathrm{~m} / \mathrm{s}$ and $3^{\circ}$ for wind direction at $20 \mathrm{~m} / \mathrm{s}$ ), and the DC/AC electricity production (Hall-effect sensors or shunts of SOLEA with an uncertainty of $1 \%$ ) over the entire year, except at night time, with a time-step of one minute (Assoa et al., 2013).

\subsection{Performance assessment of thermal models}

The comparison between the measured temperatures and the simulated ones has been done by means of statistical parameters described by Eqs. 1-5. In particular, for each model the mean bias error $(M B E)$, mean absolute error $(M A E)$, the root mean square error (RMSE), the weighted mean bias error (WMBE) and the coefficient of determination $R^{2}$ have been calculated as follows:

$$
\begin{aligned}
& M B E=\frac{1}{N} * \sum_{i=1}^{N}\left(T_{\text {sim }}^{i}-T_{\text {meas }}^{i}\right) \\
& M A E=\frac{1}{N} * \sum_{i=1}^{N}\left|T_{\text {sim }}^{i}-T_{\text {meas }}^{i}\right| \\
& R M S E=\sqrt{\frac{1}{N} \sum_{i=1}^{N}\left(T_{\text {sim }}^{i}-T_{\text {meas }}^{i}\right)} \\
& R^{2}=1-\sum_{i=1}^{N}\left(T_{\text {sim }}^{i}-T_{\text {meas }}^{i}\right)^{2} / \sum_{i=1}^{N}\left(T_{\text {sim }}^{i}-\bar{T}_{\text {meas }}\right)^{2}
\end{aligned}
$$

where $T^{i}$ denotes the PV module temperature and $N$ the number of temperature values considered.

$$
W M B E=\frac{\sum_{\mathrm{i}=1}^{\mathrm{N}}\left(\mathrm{T}_{\text {sim }}^{\mathrm{i}}-\mathrm{T}_{\text {meas }}^{\mathrm{i}}\right) * \mathrm{G}_{\text {meas }}^{\mathrm{i}}}{\sum_{\mathrm{i}=1}^{\mathrm{N}} \mathrm{G}_{\text {meas }}^{\mathrm{i}}}
$$

Note that this parameter, with respect to the mean bias error, gives more weight to the performance of thermal modelling at higher values of the irradiance, namely when there is a higher electricity production. 


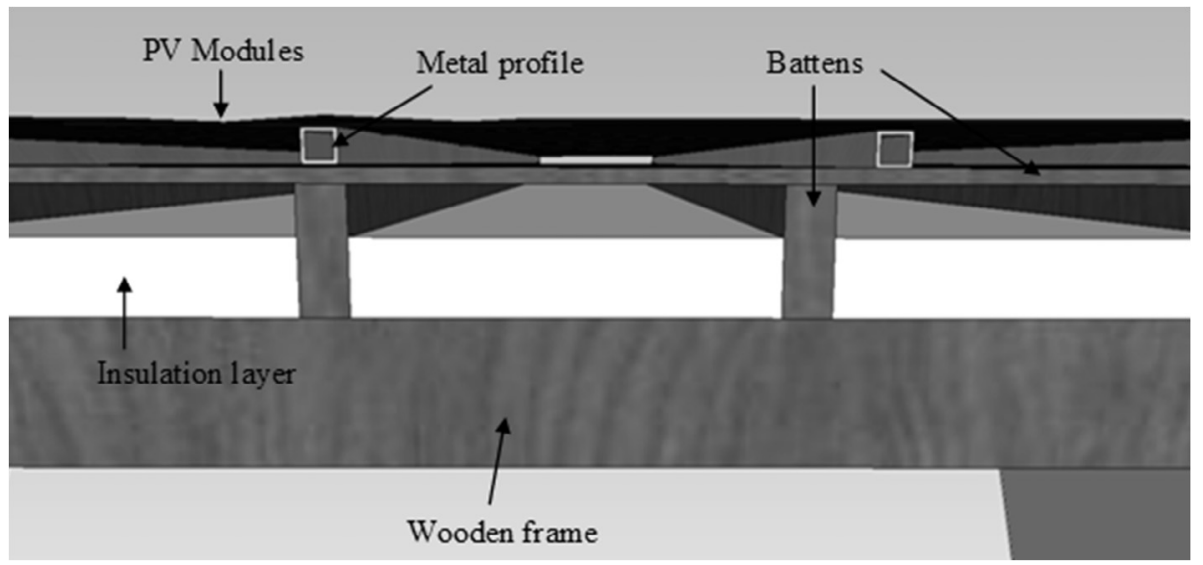

Fig. 2. Sketch of a section of the test bench.

Table 1

Layers of the PV module.

\begin{tabular}{ll}
\hline Layers of the PV module & Thickness $(\mathrm{mm})$ \\
\hline Glass & 3.2 \\
Silicon & 0.2 \\
EVA & 0.1 \\
Tedlar & 0.25 \\
Polymer & 1 \\
\hline
\end{tabular}

\section{Thermal models description}

The thermal behavior of the BIPV test bench was simulated using nine different approaches. Each model takes into account

Table 2

Main characteristics of thermal models.

\begin{tabular}{|c|c|}
\hline Model & Main features \\
\hline 1 & $\begin{array}{l}\text { Linear model: one temperature value representing the entire PV } \\
\text { panel; the difference between the PV panel operative temperature } \\
\text { and the ambient temperature is a linear function of the measured } \\
\text { irradiance }\end{array}$ \\
\hline 2 & $\begin{array}{l}\text { Lumped element model: the temperature of each layer of the PV } \\
\text { panel is simulated by solving energy balance equations; the inertia } \\
\text { terms relative to the thermal capacities of the layers materials are } \\
\text { neglected; heat transfer coefficients are constant values }\end{array}$ \\
\hline 3 & The same approach of model 2 with the inclusion of inertia terms. \\
\hline 4 & $\begin{array}{l}\text { The same approach of model } 3 \text {, but with convective heat transfer } \\
\text { coefficient relative to the panel front surface expressed as a function } \\
\text { of the measured wind velocity }\end{array}$ \\
\hline 5 & $\begin{array}{l}\text { The same approach of model } 4 \text {, taking also into account the } \\
\text { measured wind direction }\end{array}$ \\
\hline 6 & $\begin{array}{l}\text { Lumped element model: the temperature of each layer of the PV } \\
\text { panel is simulated by solving unsteady energy balance equations; } \\
\text { the measured wind velocity is taken into account for the evaluation } \\
\text { of convective heat transfer, while the measured wind direction is } \\
\text { ignored }\end{array}$ \\
\hline 7 & $\begin{array}{l}\text { Lumped element model: the temperature of each layer of the PV } \\
\text { panel is simulated by solving unsteady energy balance equations; } \\
\text { the sky temperature, and the convective heat transfer coefficients as } \\
\text { a function of wind velocity evaluated through optimization }\end{array}$ \\
\hline 8 & $\begin{array}{l}\text { Dynamic 2D model realized using the commercial software } \\
\text { TRNSYS17 and Fortran 2010. The two air gaps layers of the test } \\
\text { bench are considered as one; only a "slice" of collector along the roof } \\
\text { is modelled from the very top to the very bottom of the roof; each PV } \\
\text { module is represented by a single temperature node }\end{array}$ \\
\hline 9 & $\begin{array}{l}\text { Dynamic 2D model constructed using the commercial software } \\
\text { COMSOL Multiphysics; the geometry of the test bench was } \\
\text { simplified to a two air channels system with a } 2 \mathrm{~mm} \text { steel barrier } \\
\text { between the air channels, glass/PV on the front channel and an } \\
\text { insulated adiabatic wall at the back of the bottom channel }\end{array}$ \\
\hline
\end{tabular}

some specific parameters (such as wind velocity and sky temperature) or correlations and might neglect some other ones. Table 2 reports the main characteristics of each model.

The considered models are described in the following subsections.

\subsection{Linear model (Model 1)}

One of the most used models to evaluate the temperature of PV modules is the linear approach (Skoplaki and Palyvos, 2009). In this model, for each irradiance measurement a unique temperature value is calculated for the entire module by supposing that the difference between the module operating temperature and the ambient temperature $\Delta T$ can be expressed as a linear function of the measured irradiance (see Eq. (6)):

$\Delta T=k * G_{\text {meas }}$

Fig. 3 shows the difference between the experimental PV module temperature and the ambient temperature according to the solar irradiance measured in the tilted plane.

Data shown in Fig. 3 have been used to evaluate the parameter $k$ in Eq. (6), by optimizing the mean bias error. The resulting value is $0.02818 \mathrm{~K} . \mathrm{m}^{2} / \mathrm{W}$.

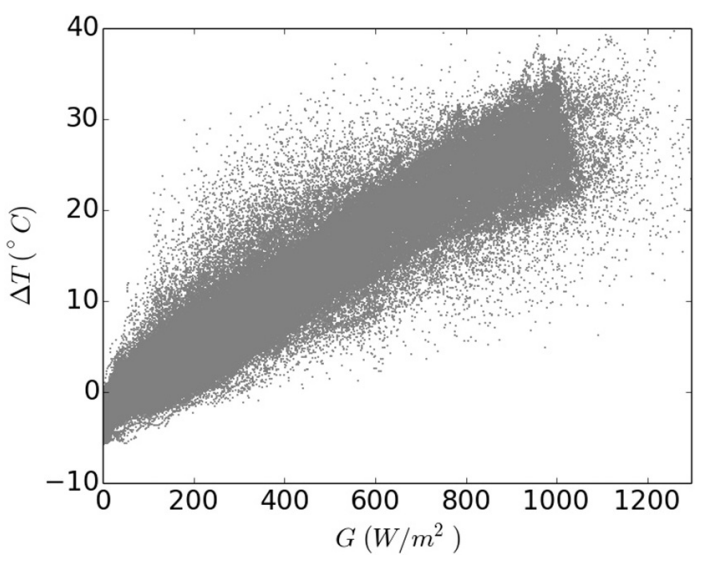

Fig. 3. Irradiance in the tilted plane versus $\Delta \mathrm{T}$. 


\subsection{Lumped elements models}

\subsubsection{Model 2}

At each time step, this model permits to evaluate the temperatures of the PV module layers by solving the energy conservation equations. It is based on the following assumptions: the radiation is absorbed only by the silicon layer; the percentage of the measured tilted irradiance that hits the silicon layer is constant and equal to $96 \%$, this last corresponding to the estimated transmission coefficient of the PV module glass at normal incidence. The efficiency of the PV module is equal to $12.5 \%$. In the energy balance equations, the inertia terms relative to the thermal capacities of the layers materials are neglected, thus only the terms relative to the conduction heat transfer are considered for the internal layers. The heat transfer coefficients relative to the module front and back surfaces include the effects of the convective and radiative heat transfer mechanisms.

With reference to the European standard EN 674:2011, they are considered constant (see Eqs. (7) and (8)).

$h_{\text {front }}=25 \mathrm{~W} / \mathrm{m}^{2} / \mathrm{K}$;

$h_{\text {back }}=7.7 \mathrm{~W} / \mathrm{m}^{2} / \mathrm{K}$.

\subsubsection{Model 3}

This approach consists of model 2 with the addition of the inertia terms in the energy balance equations of the PV module layers, and the time step relative to the discretized time derivative of temperature is the same of the measurements recording, i.e. $60 \mathrm{~s}$.

\subsubsection{Model 4}

As compared to model 3, in this case a further improvement has been applied to the solver, namely the convective heat transfer coefficient relative to the module front surface has been considered to be a linear function of the measured wind velocity, while the radiative component of $h_{\text {front }}$ remains constant and equal to $5 \mathrm{~W} /$ $\mathrm{m}^{2} / \mathrm{K}$, which corresponds to the assumption that the sky temperature is equal to the ambient one. The Jürges correlations (Jürges, 1924 ) have been adopted for the purpose (see Eqs. (9) and (10)):

for $v_{\text {wind }}<5 \mathrm{~m} / \mathrm{s}: \quad h_{\text {front,convective }}=4.0 * v_{\text {wind }}+5.6 \mathrm{~W} / \mathrm{m}^{2} / \mathrm{K}$

for $v_{\text {wind }}>5 \mathrm{~m} / \mathrm{s}: \quad h_{\text {front,convective }}=7.1 v_{\text {wind }}^{0.78} \mathrm{~W} / \mathrm{m}^{2} / \mathrm{K}$

\subsubsection{Model 5}

This approach is the same of model 4, except that also the measured wind direction $d_{\text {wind }}$ is taken into account, by using the following modified velocity in the Jürges correlations (see Eq. (11)):

$v_{\text {wind }}^{*}=v_{\text {wind }} *\left(a *\left(1 / a+\sin \left(d_{\text {wind }}-\pi / 2\right)\right)\right)$

In Eq. (10), the measured wind direction is expressed in radiant, with the zero at north, and with increasing values in the clockwise direction. Considering the small tilt angle of $15^{\circ}$, the parameter $a$ has been set to a value of 0.1 .

\subsubsection{Model 6}

In this model, the system of unsteady energy balance equations relative to the PV module layers has been solved by means of a numerical code written in $\mathrm{C}++$ that makes use of the PETSc solver as sparse matrix solver for the steady state simulations, and of an explicit scheme for transient ones.

The photovoltaic cell has been modelled considering the MPP (maximum power point) efficiency taken from the module datasheet and equal to $17 \%$ at STC, and considering the MPP power temperature coefficient constant and equal to $0.46 \% / \mathrm{K}$. Light trans- port within the module is assumed to follow the Beer-Lambert laws (Bouguer, 1729). Additionally, primary reflection losses due to changes of the refractive index for near-normal incident angles have been considered.

As to the convective heat transfer on the module front surface, in the present model the wind direction is ignored. In previous publications (Kubicek and Berger, 2011) parameterized 2d fluid dynamic simulations were performed, in which a table of PV module is situated in the calculation domain. The fluid dynamics calculation was performed, and on the multiple locations (surface element centers) the convective cooling coefficient was evaluated and exported for front and back surface independently. Multiple parameters such as wind speed (also from the backward direction), the height above ground, the tilt angle and the total height of the table were varied, to obtain a multidimensional discrete function of the front and backside heat transfer coefficients. Using numerical optimization, the unknown parameters of an approximate polynomial function of second order were fitted to the simulation data. This polynomial function was evaluated for the geometric setup to obtain the velocity dependent front and backside heat-transfer coefficients used in this publication. For calculation time limitations, no 3d expansion of this model (Wagner, 2014) was performed.

Radiative cooling is assumed to follow the Planck black body radiation for the surface temperature with a spectral constant emission coefficient. For the specific case of a roof-integrated system, the backside thermal radiation has not been modelled. Under the assumption of a homogenous ground temperature, the radiative heat flow exchanged between the module front surface and the environment is given by Eq. (12):

$\dot{q}_{r}=\varepsilon * \sigma *\left\{T_{\text {glass }}^{4}-f * T_{\text {sky }}^{4}-(1-f) * T_{\text {ground }}^{4}\right\}$

In Eq. (11), the parameter $f$ represents the view factor between the module front surface and the sky, and it is given by Eq. (13):

$f=F_{P V-s k y}=\frac{1}{2} *(1+\cos \beta)$,

where $\beta$ denotes the tilt angle. The view factor between the module front surface and the ground is (see Eq. (14)):

$F_{P V-\text { ground }}=\frac{1}{2} *(1-\cos \beta)=1-f$

The ground temperature has been assumed equal to the ambient temperature, as highly sophisticated ground temperature models would need to include the draining and evaporation cooling of the earth. Additional accuracy could be gained by regarding different view factors to shaded and illuminated ground, as well as radiation from visible module areas in the next module raw, for the case of non-building integrated generators. The sky temperature could be measured using a so-called "pyrgeometer". As this data in photovoltaic setup is typically not available, approximations based on other sites data were assumed: In clear sky conditions, the sky temperature can reach temperatures of $-20^{\circ} \mathrm{C}$, whereas for full cloud cover, the assumption that the clouds backscatter the ground temperature radiation is a common approximation. As pointed out by Martin and Berdahl (1984), one possible option is to set the sky temperature equal to the ambient temperature minus a constant offset, the so called "depression". The problem with such an approach is that this depression should be related to the amount of clouds.

Hence, in this model, the GPS position is used to calculate a theoretical irradiance value onto the module plane, which is compared to the experimentally measured irradiance. The fraction between the theoretical and experimental irradiances is called "cloudiness factor" c. If it equals one, clear sky conditions could be assumed, while for small values, the cloud cover is dense. 
Using this cloudiness factor and an assumed depression value found for a different location, the sky temperature has been assumed as (see Eq. (15)):

$T_{\text {sky }}=T_{\text {amb }}-18 * c$

Model 6 could have a decreased accuracy at low irradiance in case of a not precise evaluation of the sky temperature, of an horizontal shading of surrounding mountains or of the glass reflections at flat incident angles or of dew.

\subsubsection{Model 7}

In this case, the adopted physical model takes into account the thermal inertia of the various layers, and considers the absorbed radiation as heat generated inside the silicon layer.

In order to evaluate the heat generation, the glass transmittance and silicon layer absorbance have been both considered equal to 0.9 , with a resulting heat flux absorbed by the silicon layer equal to the $81 \%$ of the measured irradiance. The heat flux absorbed by the silicon layer has been further lowered by considering the panel efficiency. For the radiative boundary conditions, the glass surface emissivity has been assumed equal to 0.87 , the ground emissivity equal to 0.9 , and the values of emissivity of the polymer back surface and of the roof beneath equal to 0.8 . The ground and roof temperatures have been set equal to the ambient temperature, while the sky temperature has been calculated following an approach similar to the one adopted by Jones and Underwood (Jones and Underwood, 2001) and by Siddiqui et al. (Siddiqui et al., 2012):

$T_{\text {sky }}=T_{a m b}-12$

View factors have been calculated and included. Relatively to the convective boundary conditions, the effects of wind direction have not been modelled. Indeed, at the glass front surface and the polymer back surface, the convective heat transfer coefficient has been calculated as a linear function of the wind velocity (see Eqs. (17) and (18)):

$h_{\text {front, } \text {,onvective }}=0.74 * v_{\text {wind }}+12.24$

$h_{\text {back,convective }}=1.77 * v_{\text {wind }}+1.55$

The integer value subtracted to the ambient temperature in the right side of Eq. (16), and the coefficients in Eqs. (17) and (18) have been estimated from the application of an optimization tool based on a genetic algorithm, minimizing the root mean square error RMSE relative to the model back panel temperatures resulting from the simulation of four days selected randomly, namely 2011-02-07 (day 1), 2011-05-08 (day 2), 2011-08-23 (day 3), and 2011-11-03 (day 4). Many other similar linear correlations taken from the literature (Armstrong and Hurley, 2010) have been tested, none of them producing better results when used in the present model.

The energy balance equations relative to the different layers have been solved numerically by means of the implicit Euler method, and the non-linear boundary conditions have been handled using an iterative approach. Each day has been simulated separately, and for each day the initial module layers temperatures have been set equal to the first module temperature measured in the same day.

Fig. 4 shows a comparison between the experimental and the simulated temperatures relative to the above four days. In the present model, only 235 days of 365 have been simulated.

\subsection{Models using commercial solvers}

\subsubsection{Model 8}

This model has been implemented by using the solver of the commercial software TRNSYS (Klein et al., 1996). In this case, the dynamic heat balance has been performed in Fortran 2010 soft- ware and is based on a 2D nodal approach considering the following assumptions (Assoa et al., 2007; Assoa and Ménézo, 2014). The insulation layer at the underside of the air gap is assumed to be adiabatic. The two air gaps layers are considered as one. Only a "slice" of collector along the roof is modelled from the very top to the very bottom of the roof. Each PV module is represented by a single temperature node, and the air gap is uniformly discretized along the roof by means of a finite volume method. As simplifying assumption, the aerodynamic behavior in the air gap is supposed to be close to fully developed laminar flow in forced convection (with an air velocity at $0.4 \mathrm{~m} / \mathrm{s}$ and thus, a Reynolds number $R e$ lower than 2300) in a duct with constant surface heat flux. Thus, the convective heat transfer coefficient depends on a constant local Nusselt number (Incropera et al., 1990) (see Eq. (19)):

$N u=4.36$

The convective heat transfers coefficient between the ambient air and the surface of the PV modules depends on the wind velocity (MacAdams, 1954) (see Eq. (20)):

$h_{e, p v}=5.7+3.8 \cdot \mathrm{w}$

As to the radiative heat transfer, the sky temperature has been evaluated by means of the Eq. (21) (Swinbank, 1963):

$T_{\text {sky }}=0.0552 *\left(T_{a m b}\right)^{1.5}$

where, the ambient temperature $T_{a m b}$ is in Kelvin. In the air gap, the radiative heat transfer coefficient depends on the mean radiant temperature.

\subsubsection{Model 9}

A dynamic 2D model was constructed using the commercial software COMSOL Multiphysics, which is based on a Finite Element Method (FEM) solver. The geometry of the test bench was simplified to a two air channels system with a $2 \mathrm{~mm}$ steel barrier between the air channels, glass/PV on the front channel, and an insulated adiabatic wall at the back of the bottom channel. The channel is $3 \mathrm{~m}$ long, representing the 3 landscape mounted modules along the height of the system. The flow field due to buoyancy in the two channels is simulated.

The convective heat transfer coefficient relative to the front of the module has been calculated as the overlap of two contributions in parallel, namely the forced convection and the natural convection (see Eq. (22)):

$h_{\text {front, convective }}=h_{\text {forced }}+h_{\text {natural }}$

where the coefficient relative to forced convection has been evaluated using the correlation proposed by Sharples (Sharples and Charlesworth, 1998) for the windward side of a PV module (see Eq. (23)):

$h_{\text {forced }}=6.5+3.3 * v_{\text {wind }}$

The one relative to natural convection refers to the Eicker correlation (Eicker, 2003) (see Eq. (24)):

$h_{\text {natural }}=1.78 *\left(T_{P V}-T_{a m b}\right)^{1 / 3}$

As to the radiative cooling, the sky temperature has been evaluated by means of Eq. (25) (Anderson et al., 2009):

$T_{\text {sky }}=0.037536 *\left(T_{a m b}\right)^{1.5}+0.32 * T_{a m b}$

The validation of the model results has been performed by using test bench data taken only from two weeks, due to the very high computational cost, including sunny and cloudy periods, namely from May 23rd to 29th 2011, and from November 17th to 23rd 2011. 


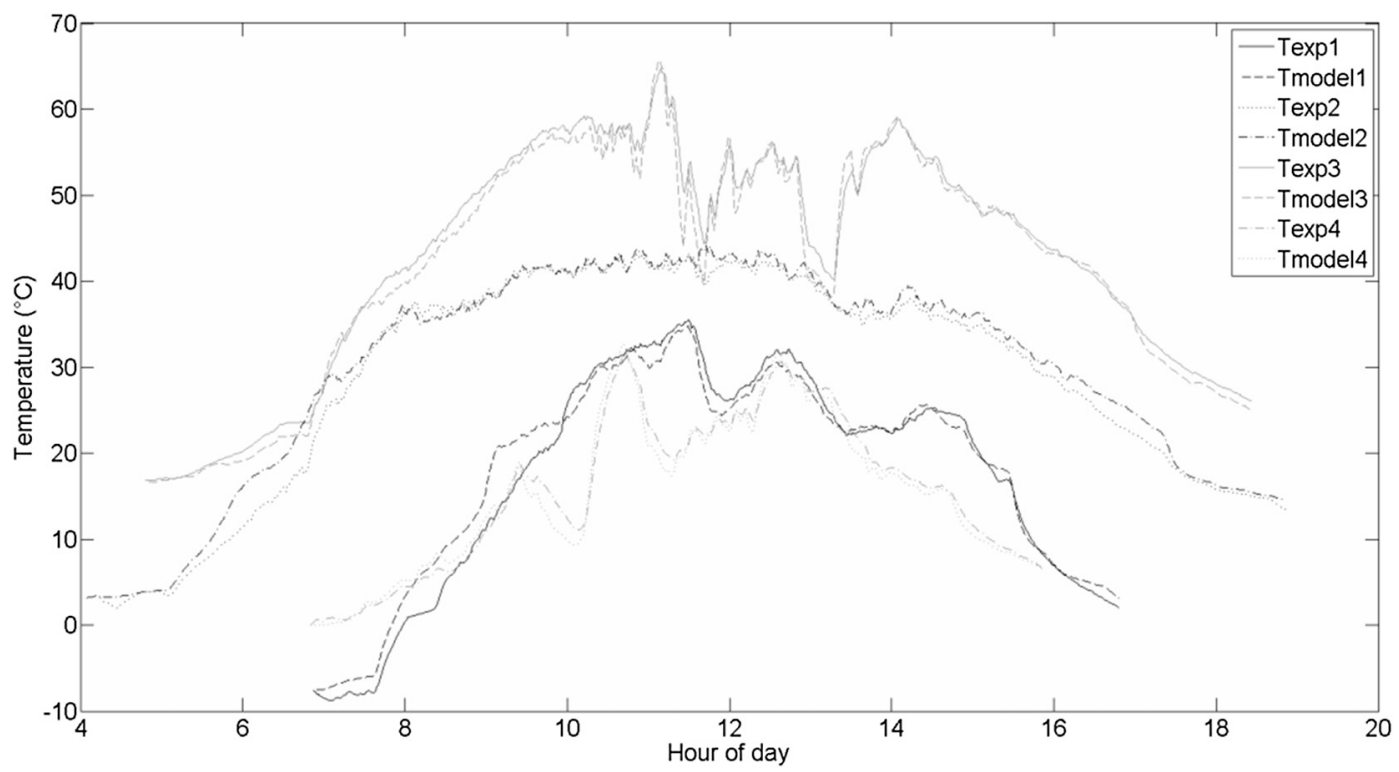

Fig. 4. Experimental and simulated temperatures.

\section{Analysis of results}

\subsection{Analysis of results over a year}

Table 3 shows the statistical results relative to all the implemented models (the night time is not included) over a year. For each model, the coefficient of determination, the root mean square error, the mean absolute error, the mean bias error, and the weighted mean bias error are reported.

For models 7 and 9, it is important to notice that they have not been obtained by using the entire set of experimental data. Thus, their comparison with other models is limited.

It can be stated that all the models implemented over the entire year on the considered polycrystalline BIPV system allow achieving a good prediction of the PV module back panel temperature, with a coefficient of determination $R^{2}$ relative to the linear model equal to about $95 \%$. Analyzing the results relative to the models from 2 to 9 , it can be noticed that there is a gradual and consistent improvement of results from model $2\left(R^{2}=95.1 \%\right)$ to model 4 $\left(R^{2}=97.2 \%\right)$. This is due to the addition, compared to model 2, of the inertia effects in model 3 (increase of $R^{2}$ of $0.9 \%$ ), and of the inertia effects and the wind velocity correlation for the convective heat transfer at the front surface of the PV module in model 4 (increase of $\mathrm{R}^{2}$ of $2.1 \%$ ). The comparison between the results of model 4 and 5 indicates that the effects of wind direction on the convective heat transfer at the front surface of the module leads to a reduced improvement of results (increase of $\mathrm{R}^{2}$ of $0.2 \%$ compared to model 4 or $2.3 \%$ compared to model 2 ).

Considering empirical equations for the heat transfer coefficients between PV modules surface and the air in the gap (see model 8) gives also reduced improvement of the results $\left(R^{2}\right.$ increases of $0.6 \%$ ) compared to model 5 but a more important improvement compared to model 2 ( $\mathrm{R}^{2}$ increases of $2.7 \%$ ).

The optimization of the heat transfer coefficients between PV modules and the exterior (based on wind velocity and sky temperature) realized in models 6 and 7 involves an improvement of results. For model $6, \mathrm{R}^{2}$ increases of $0.7 \%$ compared with model 5 , and of $3 \%$ compared to model 2 , while for model $7, \mathrm{R}^{2}$ increases of $1.2 \%$ compared with model 5 , and of $3.5 \%$ compared to model 2 .

The consideration of the results obtained with model 9 on the two weeks highlights that models effectiveness can strongly depend on the boundary conditions. Thus, a thermal model could be very accurate in some periods with certain boundary conditions and less accurate in other periods with different ones. By the way, comparing the corresponding values of $M B E$ and $W M B E$, it can be noticed that, at high values of the irradiance, when electrical energy production of the PV modules is most influenced by their temperature, models from 1 to 6 are less effective including linear model. Model 7 and model 8 present a better behavior and thus could provide to engineers and researchers a more accurate prediction of PV modules temperature in these periods and in the considered integration configuration.

Table 3

Statistical results of all the thermal models over a year.

\begin{tabular}{|c|c|c|c|c|c|}
\hline Model & $\mathrm{R}^{2}[\%]$ & $\operatorname{RMSE}\left[{ }^{\circ} \mathrm{C}\right]$ & $\operatorname{MAE}\left[{ }^{\circ} \mathrm{C}\right]$ & $\operatorname{MBE}\left[{ }^{\circ} \mathrm{C}\right]$ & WMBE $\left[{ }^{\circ} \mathrm{C}\right]$ \\
\hline 1 & 95.2 & 3.29 & 2.44 & 1.03 & 1.00 \\
\hline 2 & 95.1 & 3.34 & 2.49 & -0.17 & -1.26 \\
\hline 3 & 96.0 & 3.01 & 2.31 & -0.26 & -1.51 \\
\hline 4 & 97.2 & 2.51 & 1.91 & 0.37 & -0.77 \\
\hline 5 & 97.4 & 2.42 & 1.82 & 0.46 & -0.55 \\
\hline 6 & 98.1 & 2.09 & 1.52 & -0.04 & 0.36 \\
\hline 7 & 98.6 & 1.80 & 1.40 & 0.44 & 0.15 \\
\hline 8 & 97.8 & 2.23 & 1.79 & -0.74 & -0.07 \\
\hline 9 (1st week) & 97.2 & 2.38 & 1.92 & 1.53 & - \\
\hline 9 (2nd week) & 91.1 & 3.17 & 2.30 & 1.60 & - \\
\hline
\end{tabular}




\subsection{Analysis of seasonal results}

The same statistical analysis was performed considering the four seasons separately. Since model 9 has been implemented only in two weeks falling in different seasons, its seasonal results are similar to the statistics reported in the previous section and are not reported in this one. Tables $4-8$ show, for thermal models 1 to 8 , the statistics relative to the winter season (from 21 st of December to 20th of March), the spring season (from 21st of March to 20th of June), the summer season (from 21st of June to 21st of September), the autumn season (from 22nd of September to 20th of December), and the difference between the coefficients of determination relative to the entire year and the ones relative to the four seasons, respectively.

Table 8 indicates that the linear model (model 1) exhibits a better behavior in the autumn season, while its worst results are those relative to the summer season. Similar considerations can be made for model 2, namely the lumped element model without the inertia terms. As stated in the previous section, the addition of the inertia term in model 3 permitted to obtain an improvement of results, and Tables 4-7 show that this improvement is obtained in all seasons. Further, considering the results in Table 8 and those relative to the spring and summer seasons in Tables 5 and 6, respectively, it can be noticed that the addition of inertia terms in model 3 has involved a sensible enhancement of simulation results during the hot seasons, as compared to model 2, and this is the main reason explaining the best performance of model 3 with respect to model 2 over the entire year. By comparing the results relative to models 3,4 and 5, it can be argued that the improvement of simulation results obtained by evaluating the heat transfer coefficient relative to the module front surface as a function of the measured wind velocity, as made in models 4 and 5, is sensible in all seasons. Nevertheless, as already stated previously, the dependence of the convective heat transfer on the wind direction considered in model 5 doesn't involve a sensible improvement of results with respect to model 4. Finally, as concerns the models presenting the best annual results, namely models 6,7 , and 8 , which also consider a sky temperature different from the ambient temperature in the evaluation of the radiative heat transfer, it can be noticed that they exhibit a better behavior during the hot seasons. It can be also observed that the results of model 9 are those presenting the largest difference between the hot seasons results and the cold seasons ones (see Table 3).

\section{Ongoing studies considering detailed optical modelling}

For all thermal models considered in this work, the optical properties of BIPV modules are supposed to be constant. With the aim of further increasing the accuracy of the modelling, various studies are being conducted in order to integrate the optical behavior of BIPV modules within thermal models. The fundamentals of an analytical model for this optical description are given in what follows.
The absorptivity of encapsulated PV cells, $\alpha_{\text {cell }}$ is the key parameter to determine the cell temperature, $T_{c}$, which critically affects the electrical performance of the cell. When a fundamental approach is followed (e.g. Fung and Yang, 2008), the formulation of the thermal balance and the determination of $T_{c}$ requires solving in advance the optical problem comprising the encapsulation materials (glass, polymers and coatings). Cell absorptivity also appears in alternative approaches, such as semi empirical formulae or simplified modelling leading to correlations of the cell temperature with standard weather variables and material or system properties (Skoplaki and Palyvos, 2009 and references therein) (Davis et al., 2011). Due to the complexity of the optical-thermal problem, especially when time-dependent boundary conditions (irradiation, weather variables) are considered and the angular dependence is included in the physical equations, the use of numerical analysis is needed, with several degrees of accuracy. The absorptivity of the PV cell can then be estimated from different modelling assumptions, ranging from a value based on a simplified optical study and depending of the encapsulation materials (e.g., a nominal value, (Davis et al., 2011), or a polynomial adjustment, etc.), to be implicitly included in numerical analysis combining ray-tracing and MEF techniques (Sprenger et al., 2016, or this research).

However, it is possible to obtain an intermediate solution to the optical modelling, giving closed analytical expressions for the absorptivities (and also for the short-wave energy fluxes within the system), improving the usual simplified solutions. This kind of modelling has been recently revisited and applied to photovoltaic modules by Baenas and Machado (2016) and Machado et al. (2016). In this particular case, the method is based on the classic matrix transfer methods (limited to the modelling features of the glazing standards EN 410, ISO 9050), which allow a systematic way to formulate and solve the equation system of an optical system composed by glass substrates, interlayers and coatings. The iterative calculation of the layer-by-layer absorption (Siegel, 1973) (ISO 15099, standard) can be performed taking into consideration the influence of coatings (e.g. anti-reflective coating in the encapsulation material-cell optical interface and/or in air-glass one), which is generally ignored in simplified solutions. The method requires the spectrophotometric (UV-Vis-NIR, at nearly normal incidence) characterization of the different component layers, from basic configurations (Rubin, 1998) (EN 410 standard). The optical parameters of the system are then obtained depending on the internal spectral properties of the components.

In particular, the $\alpha_{\text {cell }}$ absorptivity depends on the internal reflectivity in the encapsulation material-cell optical interface, $r_{\text {cell }}$ (see Eqs. (26) and (27)). In the general case, the available equation system for a glazing system has three equations for each wavelength (one for the energy transmittance $T$ and front and back reflectances, $R_{f}$ and $R_{b}$ respectively), allowing the spectral characterization of a component. Given that a traditional PV module is an opaque system, only the front reflectance is available in order to obtain $r_{\text {cell }}$, and the transfer matrix of the cell (opaque compo-

Table 4

Statistical results of all the thermal models in winter period.

\begin{tabular}{|c|c|c|c|c|c|}
\hline Model & $\mathrm{R}^{2}[\%]$ & $\operatorname{RMSE}\left[{ }^{\circ} \mathrm{C}\right]$ & $\operatorname{MAE}\left[{ }^{\circ} \mathrm{C}\right]$ & $\operatorname{MBE}\left[{ }^{\circ} \mathrm{C}\right]$ & WMBE $\left[{ }^{\circ} \mathrm{C}\right]$ \\
\hline 1 & 93.5 & 2.52 & 1.79 & 0.78 & 0.58 \\
\hline 2 & 93.2 & 2.58 & 1.85 & 0.02 & -0.97 \\
\hline 3 & 93.9 & 2.43 & 1.75 & -0.02 & -1.13 \\
\hline 4 & 96.0 & 1.97 & 1.39 & 0.49 & -0.22 \\
\hline 5 & 96.2 & 1.92 & 1.35 & 0.54 & -0.09 \\
\hline 6 & 95.3 & 2.14 & 1.42 & 0.66 & 1.50 \\
\hline 7 & 96.8 & 1.80 & 1.49 & 0.77 & 0.31 \\
\hline 8 & 93.3 & 2.56 & 2.15 & -1.49 & -0.54 \\
\hline
\end{tabular}


Table 5

Statistical results of all the thermal models in spring period.

\begin{tabular}{|c|c|c|c|c|c|}
\hline Model & $\mathrm{R}^{2}[\%]$ & $\operatorname{RMSE}\left[{ }^{\circ} \mathrm{C}\right]$ & $\operatorname{MAE}\left[{ }^{\circ} \mathrm{C}\right]$ & $\operatorname{MBE}\left[{ }^{\circ} \mathrm{C}\right]$ & WMBE $\left[{ }^{\circ} \mathrm{C}\right.$ \\
\hline 1 & 93.4 & 3.54 & 2.74 & 1.40 & 1.31 \\
\hline 2 & 93.5 & 3.51 & 2.71 & -0.08 & -1.17 \\
\hline 3 & 94.7 & 3.18 & 2.52 & -0.17 & -1.40 \\
\hline 4 & 96.1 & 2.72 & 2.16 & 0.23 & -1.09 \\
\hline 5 & 96.4 & 2.60 & 2.04 & 0.37 & -0.81 \\
\hline 6 & 97.9 & 1.98 & 1.47 & -0.01 & 0.34 \\
\hline 7 & 98.4 & 1.76 & 1.32 & 0.17 & 0.15 \\
\hline 8 & 97.7 & 2.10 & 1.62 & -0.44 & -0.18 \\
\hline
\end{tabular}

Table 6

Statistical results of all the thermal models in summer period.

\begin{tabular}{|c|c|c|c|c|c|}
\hline Model & $\mathrm{R}^{2}[\%]$ & $\operatorname{RMSE}\left[{ }^{\circ} \mathrm{C}\right]$ & $\operatorname{MAE}\left[{ }^{\circ} \mathrm{C}\right]$ & $\operatorname{MBE}\left[{ }^{\circ} \mathrm{C}\right]$ & WMBE $\left[{ }^{\circ} \mathrm{C}\right.$ \\
\hline 1 & 92.2 & 3.71 & 2.77 & 1.02 & 1.08 \\
\hline 2 & 92.0 & 3.76 & 2.86 & -0.37 & -1.31 \\
\hline 3 & 93.8 & 3.32 & 2.60 & -0.49 & -1.64 \\
\hline 4 & 95.8 & 2.74 & 2.12 & 0.29 & -0.75 \\
\hline 5 & 96.0 & 2.65 & 2.02 & 0.39 & -0.54 \\
\hline 6 & 97.1 & 2.26 & 1.73 & -0.74 & -0.12 \\
\hline 7 & 98.1 & 1.84 & 1.43 & 0.36 & 0.04 \\
\hline 8 & $97.7 \%$ & 2.02 & 1.61 & -0.34 & 0.20 \\
\hline
\end{tabular}

Table 7

Statistical results of all the thermal models in autumn period.

\begin{tabular}{|c|c|c|c|c|c|}
\hline Model & $\mathrm{R}^{2}[\%]$ & $\operatorname{RMSE}\left[{ }^{\circ} \mathrm{C}\right]$ & $\operatorname{MAE}\left[{ }^{\circ} \mathrm{C}\right]$ & $\operatorname{MBE}\left[{ }^{\circ} \mathrm{C}\right]$ & WMBE $\left[{ }^{\circ} \mathrm{C}\right.$ \\
\hline 1 & 94.9 & 2.54 & 1.84 & 0.51 & -0.22 \\
\hline 2 & 93.8 & 2.80 & 2.01 & -0.20 & -1.76 \\
\hline 3 & 94.7 & 2.58 & 1.87 & -0.28 & -1.95 \\
\hline 4 & 96.6 & 2.06 & 1.52 & 0.67 & -0.03 \\
\hline 5 & 96.8 & 2.01 & 1.48 & 0.68 & 0.01 \\
\hline 6 & 97.1 & 1.93 & 1.35 & 0.47 & 0.92 \\
\hline 7 & 97.4 & 1.81 & 1.42 & 0.76 & 0.31 \\
\hline 8 & 95.1 & 2.47 & 2.08 & -1.34 & -0.09 \\
\hline
\end{tabular}

Table 8

Difference between the annual coefficient of determination ${ }^{2}$ and the ones relative to the four seasons.

\begin{tabular}{|c|c|c|c|c|}
\hline Model & $\Delta \mathrm{R}^{2}[\%]$ Winter & $\Delta \mathrm{R}^{2}[\%]$ Spring & $\Delta \mathrm{R}^{2}[\%]$ Summer & $\Delta \mathrm{R}^{2}[\%]$ Autumn \\
\hline 1 & 1.7 & 1.8 & 3.0 & 0.3 \\
\hline 2 & 1.9 & 1.6 & 3.1 & 1.3 \\
\hline 3 & 2.1 & 1.3 & 2.2 & 1.3 \\
\hline 4 & 1.2 & 1.1 & 1.4 & 0.6 \\
\hline 5 & 1.2 & 1.0 & 1.4 & 0.6 \\
\hline 6 & 2.8 & 0.2 & 1.0 & 1.0 \\
\hline 7 & 1.8 & 0.2 & 0.5 & 1.2 \\
\hline 8 & 4.5 & 0.1 & 0.1 & 2.7 \\
\hline
\end{tabular}

nent) is not defined. In such situation, the singular solutions of the equation systems must be considered. For instance, considering a typical PV module (consisting of uncoated glass, polymeric encapsulation with refractive index similar to that of the glass substrate, and opaque PV cell), the following expressions are obtained (Baenas and Machado, 2016).

$r_{\text {cell }}=\frac{R_{f}-r_{s}}{\tau_{s}^{2} \tau_{L}^{2}\left(1-2 r_{s}+R_{f} r_{s}\right)}$

$\alpha_{\text {cell }}=\left(1-r_{s}\right)\left(1-r_{\text {cell }}\right) \frac{\tau_{s} \tau_{L}}{1-r_{s} r_{\text {cell }} \tau_{s}^{2} \tau_{L}^{2}}$,

$r$ and $\tau$ being, respectively, the reflectivity and transmissivity (due to Beer's law) of the components glass substrate ( $s$ ) and polymeric interlayer $(L)$. This kind of expressions can also be achieved by classic ray-tracing algorithm (Krauter and Hanitsch, 1996),
(Rubin et al., 1998), but the systematic treatment followed is directly applicable to more complex PV cell encapsulation schemes, and may be implemented in any all-purpose symbolic computation system.

Once a specific optical modelling for the PV module is proposed, and the components have been characterized by spectrophotometry, it is possible to perform an indirect experimental validation of the model, through the measurement of the short-circuit density current of the module, $J_{s c}$ (ASTM E1021-15 standard). This avoids the complex validation through thermal measurements (e.g., center-glass surface temperatures), and it is based in the relationship between the PV module efficiency and the optical modelling of its cover materials. The $J_{s c}$ can be obtained from the original incoming photon flux $(\phi)$, the internal quantum efficiency of the cell (IQE, measured in air) and $\alpha_{\text {cell }}$ parameter (Machado et al., 2016). 


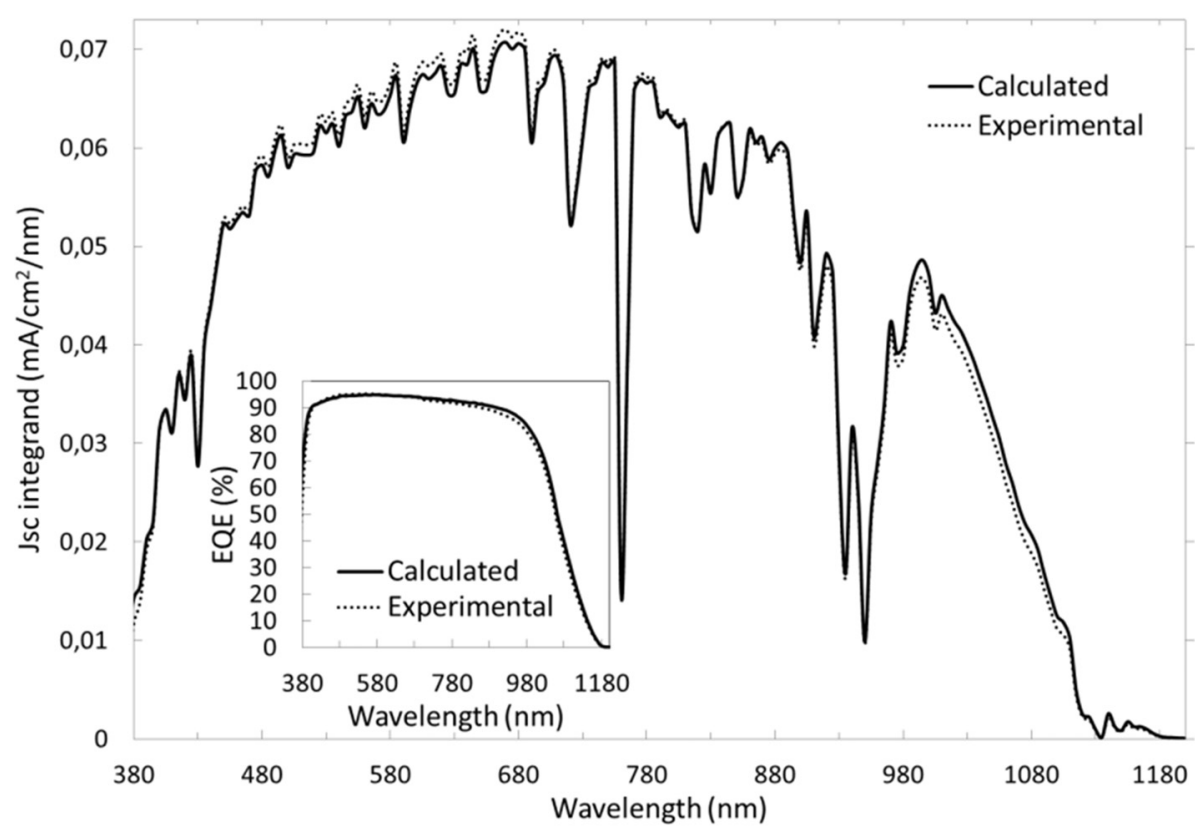

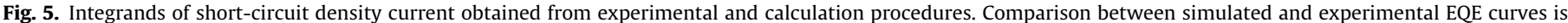
shown as an insert.

$J_{s c}=q \int_{\lambda_{1}}^{\lambda_{2}} \phi(\lambda) \operatorname{IQE}(\lambda) \alpha_{\text {cell }}(\lambda) d \lambda$,

where $\left[\lambda_{1}, \lambda_{2}\right]$ are the wavelength interval considered and $q$ is the elementary charge.

As an example, Fig. 5 (Machado et al., 2016) shows the good agreement between the calculated and experimental spectral integrand of $J_{s c}$ and external quantum efficiency for a silicon cell encapsulated with low-iron glass and EVA polymer.

\section{Conclusion}

In this work, several models developed and implemented within the European project SOPHIA in order to thermally characterize PV modules in a partially integrated BIPV system configuration have been presented. For this purpose, different simplified and detailed approaches have been considered, including a linear model. The validation of the thermal models, performed by comparing the simulation results with experimental data obtained on a test bench over a year, indicates that all the models implemented allow achieving a good prediction of the PV modules back surface temperature, with the minimum value of the coefficient of determination $R^{2}$ around $95 \%$.

The observation of weighted mean bias error WMBE and the accuracy analysis on a seasonal basis have also shown that the accuracy of the considered thermal models strongly depends on the season weather conditions and more precisely on the incident solar irradiance magnitude.

In the present work, the obtained results have indicated that the wind direction has a low influence on the accuracy of the thermal results. New correlations are proposed for the convective heat transfer coefficients based on the measured wind velocity, and for the sky temperature evaluation as concerns the radiative heat transfer. These correlations have been derived by comparing the numerical and experimental values in order to optimize the accuracy of the thermal results.

As further studies, this thermal analysis will be applied to different BIPV system configurations and operative conditions. Also, the impact of the accuracy of BIPV systems thermal models on the accuracy of the prediction of the electrical energy produced will be evaluated using an electrical model depending on solar irradiance and PV module temperature.

\section{Acknowledgements}

The experimental data used for the thermal simulation of BIPV system behavior were obtained in the framework of the project Performance BIPV supported by the French research agency (ANR), within the research program ANR HABISOL. Authors are grateful to the project partners CSTB, CEA, CNRS, Transénergie and Cythelia and to the private companies that provided the materials for the test benches. Authors would like to thank the European Community that supported the SOPHIA project with the funding of FP7-SOPHIA grant agreement $n^{\circ} 262533$.

\section{References}

Anderson, TN, Duke, M. Morrison, G.L Carson, JK, 2009. Performance of a building integrated photovoltaic / thermal (BIPVT) solar collector. Solar Energy $83,445-455$.

Armstrong, S., Hurley, W.G., 2010. A thermal model for photovoltaic panels under varying atmospheric conditions, 2010. Appl. Therm. Eng. 30, 1488-1495.

Assoa, Y.B., Ménézo, C., Fraisse, G., Yézou, R., Brau, J., 2007. Study of a new concept of photovoltaic/thermal hybrid collector. Solar Energy 81, 1132-1143.

Assoa, Y.B., Guiot, T., Gaillard, L., et al., 2013. Performance of Residential Roof BIPV System Subject to Building Integration Codes: Dynamic Modelling and Experimental Analysis, 28th EUPVSEC. France, Paris.

Assoa, Y.B., Ménézo, C., 2014. Dynamic study of a new concept of photovoltaic thermal hybrid collector. Solar Energy 107, 637-652.

Aste, N., Del Pero, C., Leonforte, F., 2016. The first Italian BIPV project: Case study and long-term performance analysis. Solar Energy 134, 340-352.

ASTM E1021-15:2015 (International Standard). Standard Test Method for Spectral Responsivity Measurements of Photovoltaic Devices.

Baenas, T., Machado, M., 2016. Optical model for multilayer glazing systems: Application to laminated glass and photovoltaic modules. Solar Energy 125, 256-266.

Bouguer P., 1729. Essai d'optique sur la gradation de la lumière, pp. 16-22, Paris, France: Claude Jombert.

Chae, Y.T. Kim, J., Park, H., Shin, B., 2014 Building energy performance evaluation of building integrated photovoltaic (BIPV) window with semi-transparent solar cells. Appl. Energy 129, 217-227.

Chatzipanagi, A., Frontini, F., Virtuani, A., 2016. BIPV-temp: a demonstrative Building Integrated Photovoltaic installation. Appl. Energy 173, 1-12.

Chow, T.T., 2003. Performance analysis of photovoltaic-thermal collector by explicit dynamic model. Solar Energy 75, 143-152. 
Davis, M.W., Hunter, Fanney A., Dougherty, B.P., 2003. Measured versus predicted performance of building integrated photovoltaic. J. Solar Energy Eng. 125, 2127.

Davis, M.W., Hunter, A., Dougherty, B.P., 2011. Prediction of building integrated photovoltaic cell temperatures. J. Solar EnergyEng. 123, 200-210.

Debbarma, M., Sudhakar, K., Baredar, P., 2017. Thermal modeling, exergy analysis, performance of BIPV and BIPVT: a review. Renew. Sustain. Energy Rev. 73 1276-1288.

Drif, M., Mellit, A., Aguilera, J., Pérez, P.J., 2012. A comprehensive method for estimating energy losses due to shading of GC-BIPV systems using monitoring data. Solar Energy 86, 2397-2404.

Eicker, U., 2003. Solar Technologies for Buildings. Wiley.

EN 410:2011 (European Standard). Glass in building. Determination of luminous and solar characteristics of glazing.

Fung, T.Y.Y., Yang, H., 2008. Study on thermal performance of semitransparent building - integrated photovoltaic glazings. Energy Build. 40, 341-350.

Gan, G., 2009. Numerical determination of adequate air gaps for building-integrated photovoltaics. Solar Energy 83, 1253-1273.

Incropera, F.P., DeWitt, D.P., et al., 1990. Introduction to Heat Transfers. John Wiley and Sons, New York.

ISO 9050:2003 (International Standard), 2003. Determination of light transmittance, solar direct transmittance, total Solar Energy transmittance, ultraviolet transmittance and related glazing factors.

ISO 15099:2003 (International Standard). 2003. Thermal performance of windows, doors and shading devices - Detailed calculations.

Jones, A.D., Underwood, C.P., 2001. A thermal model for photovoltaic systems. Solar Energy 70, 349-359.

Jürges W., 1924. The heat transfer at a flat wall (Der Wärmeübergang an einer ebenen Wand), Beihefte zum Gesundh.-Ing. 1, vol. 19.

Kaiser, A.S., Zamora, B., Mazón, R., García, J.R., Vera, F., 2014. Experimental study of cooling BIPV modules by forced convection in the air channel. Appl. Energy 135, 88-97.

Klein et al., 1996. TRNSYS Reference Manual. Solar Energy Laboratory. Madison, United States: University of Wisconsin.

Krauter, S., Hanitsch, R., 1996. Actual optical and thermal performance of PV modules. Solar Energy Mater. Solar Cells 41-42, 557-574.

Kubicek B., Berger K.A., 2011. Ab initio simulation of the PV energy production dependence on module materials and layering, Proceedings of the European Photovoltaic Solar Energy Conference and Exhibition (EU PVSEC), Hamburg.

Lamnatou, Chr., Mondol, J.D., Chemisana, D., Maurer, C., 2015. Modelling an simulation of Building-Integrated solar thermal systems: behaviour of the system. Renew. Sustain. Energy Rev. 45, 36-51.

Lu, L., Yang, H.X., 2010. Environmental payback time analysis of a roof-mounted buildings-integrated photovoltaic system in Hong-Kong. Appl. Energy 87, 3625-3631.

MacAdams, W.H., 1954. Heat Transmission. McGraw-Hill Book Company, New York.
Machado, M., Baenas, T., Yurrita, N., 2016. Optical model for multilayer glazing systems: experimental validation through the analytical prediction of encapsulation-induced variation of PV modules efficiency. Solar Energy 135, 77-83.

Martin, M., Berdahl, P., 1984. Characteristics of infrared sky radiation in the United States. Solar Energy 33, 312.

Masa-Bote, D., Caamaño-Martín, E., 2014. Methodology for estimating building integrated photovoltaics electricity production under shadowing conditions and case study. Renew. Sustain. Energy Rev. 31, 492-500.

Pantic, L.S., Pavlovi, T.M., Milosavljevi, D.D., et al., 2016. The assessment of different models to predict solar module temperature, output power and efficiency for Nis, Serbia. Energy 109, 38-48.

Rubin, M., Rottkay, K.V., Powles, R., 1998. Window Optics. Solar Energy 62, 149-161.

Sharples, S., Charlesworth, P.S., 1998. Full-scale measurements of wind-induced convective heat transfer from a roof-mounted flat plate solar collector. Solar Energy 62, 69-77.

Siddiqui, M.U., Arif, A.F.M., Kelley, L., Dubowsky, S., 2012. Three-dimensional thermal modeling of a photovoltaic module under varying conditions. Solar Energy 86, 2620-2631.

Siegel, R., 1973. Net radiation method for transmission through partially transparent plates. Solar Energy 15, 273-276.

Skoplaki, E., Palyvos, J.A., 2009. Operating temperature of photovoltaic modules: a survey of pertinent correlations. Renew. Energy 34, 23-29.

Sprenger, W., Wilson, H.R., Kuhn, T.E., 2016. Electricity yield simulation for the building-integrated photovoltaic system installed in the main building roof of the Fraunhofer Institute for Solar Energy Systems ISE. Solar Energy 135, 633643.

Stamenic, L., Smiley, E., Karim, K., 2004. Low light conditions modelling for building integrated photovoltaic (BIPV) systems. Solar Energy 77, 37-45.

Swinbank, W.C., 1963. Long wave radiation from clear skies. Quartely J. Royal Meteorol. Soc. 89, 1-339.

Tuza, A.O., Mahieddine, E., 2014. A Comparative analysis of PV module temperature Models. Energy Procedia 62, 694-703.

Trinuruk, P., Sorapipatana, C., Chenvidhya, D., 2009. Estimating operating cell temperature of BIPV modules in Thailand. Renew. Energy 34, 2515-2523.

Wagner, M., 2014. 3-Dimensional Simulated Infrared Thermography of PV Modules Diploma Theses. technical university of Vienna.

Wang, Y., Tian, W., Ren, J., Zhu, L., Wang, Q., 2005. Influence of a building's integrated-photovoltaics on heating and cooling loads. Appl. Energy 83, 9891003.

Yoo, S.-H., 2011. Simulation for an optimal application of BIPV through parameter variation. Solar Energy 85, 1291-1301.

Zhang, R., Mirzaei, P.A., Carmeliet, J., 2017. Prediction of the surface temperature of building-integrated photovoltaics: development of a high accuracy correlation using computational fluid dynamics. Solar Energy 147, 151-163. 